\title{
Assessment \& Improvement of Children Road Safety: A Pyramid \& Honeycomb Structure Approach
}

\author{
Khaled Abbas \\ Professor and Former Dean of Egypt National Institute of Transport, Cairo, Egypt \\ Email:k.abbas@tpteh.com, Kaabbas13@yahoo.com
}

How to cite this paper: Abbas, K. (2017) Assessment \& Improvement of Children Road Safety: A Pyramid \& Honeycomb Structure Approach. Journal of Transportation Technologies, 7, 240-260. https://doi.org/10.4236/jtts.2017.73017

Received: March 6, 2017

Accepted: May 29, 2017

Published: June 1, 2017

Copyright $\odot 2017$ by author and Scientific Research Publishing Inc. This work is licensed under the Creative Commons Attribution-NonCommercial International License (CC BY-NC 4.0). http://creativecommons.org/licenses/by-nc/4.0/ (c) (i) \& Open Access

\begin{abstract}
In this research, a 4 hierarchical pyramid structure approach is proposed to assess children road safety. The first is referred to as the road safety pyramid representing children road safety components and levels including root, at accident and post accident levels and factors. The second, referred to as the children road safety assessment pyramid, includes 3 cornerstones that are required to represent a detailed methodological children road safety diagnostics. These 3 cornerstones include children safety culture, safety indicators and accident data analysis. The third pyramid, referred to as the children road safety indicators, shows the levels and types of indicators that when computed can be used for in depth analysis and historical comparison of children road safety. The core of the paper is the development of a conceptual model of factors affecting the road behavior of children including traffic exposure and experience, cognitive skills and abilities, perceptual skills, knowledge and attitude. Towards this end, the paper presents the fourth pyramid, referred to as the children road safety behavior pyramid. This includes a 7-level hierarchal structure starting from exposure leading to experience and then skills/abilities, to knowledge to perception to attitudes and eventually culminating into children road safety behavior. The paper concludes by developing a generic integrated children road safety package of policies, measures, initiatives. The package is composed of 18 fields of action. In pursuing such integrated safety package this research also enhanced the classical 3Es concept (Engineering-Education-Enforcement) and introduced instead the 14Es honeycomb structure including (Engineering-Education-Environment-Enforcement-Egalitarianism-Exposure-Ethics-Emergency-Ergonomics-Enco uragement-Empowerment-Enabling-Economics-Evaluation). All in all this is meant to act as a generic benchmark guide/checklist for countries in compiling and tailoring children road safety programmes.
\end{abstract}




\section{Keywords}

Children, Road Safety, Pyramid, Honeycomb, Assess, Improve

\section{Introduction}

In many countries and cities of the world, traffic accidents are a major cause of injuries and fatalities. Road users whether adult or children, male or female, drivers, pedestrians, passengers are all involved in road accidents. According to [1], road accidents involving pedestrians constitute almost 50 percent of all accident occurrences. In general, pedestrians are considered to be vulnerable users of the road system. Furthermore, there are certain types of pedestrians that are highly vulnerable to road accidents. These include: children, the elderly, and mobility handicapped people.

According to [1], every 4 minutes a child is prematurely lost on the roads of this world, while many more are injured, often severely. This causes enormous grief, pain and suffering for families and friends of impacted children as well as other economic losses. The records show that accidents involving school children contribute a high percentage of the total accidents worldwide. The WHO statistics shows that in the age of 5 - 9 road traffic injuries are ranked as 4 as the major cause of death while in the age of $10-14$ it is number 3 and in the age of 15 to 18 it is number one cause. In this research a generic pyramid structure approach is proposed to assess children road safety. The structure is composed of 4 hierarchical pyramids. The first, referred to as the road safety pyramid, is meant to represent the road safety components and levels in a comprehensive and structured manner. It describes the factors constituting children road safety including root, at accident and post accident factors.

The second pyramid, referred to as the children road safety assessment pyramid, shows the 3 main cornerstones required to represent a detailed methodological children road safety diagnostics. The first corner involves assessing the road safety culture; the second corner covers the computation and analysis of children road safety generic indicators while the third corner includes compiling and analyzing children accident records. The road safety culture can be represented through 14 aspects, namely: Political, Institutional, Safety Lobbying, Safety Research, Engineering, Accident Management System, Evaluation, Behavior, Legislation, Enforcement and Standards, Emergency, Education, Mass Media, Coordination and Cooperation. The third pyramid representing the children road safety indicators, shows the levels and types of children road safety indicators that when computed can be used for in depth analysis and historical comparison. Additionally such indicators can be used for cross-sectional snap shot comparison among countries, cities and provinces.

At the core of the paper is the development of a conceptual model of factors affecting the road behavior of children. Towards this end, the paper presents the fourth pyramid, referred to as children road safety behavior pyramid. This in- 
cludes a 7-level hierarchal structure starting from exposure leading to experience to skills/abilities, to knowledge to perception to attitudes and eventually culminating in children road safety behavior. These factors should be targeted to enhance the existing levels of children road safety behavior. Improvement of these factors act as core basis for developing children road safety packages covering aspects such as education and training, engineering, legislation and enforcement, etc.

The paper concludes by developing a generic integrated children road safety package of policies, measures, actions $\&$ initiatives. This is meant to act as a benchmark guideline/check list for countries across the world in compiling and tailoring children road safety programmes that are meant to enhance the traffic behavior of children as well as to improve their road environment. The package is composed of 18 fields of actions namely: institutional, legislation, enforcement, land use planning and management, travel demand management, road infrastructure improvement, traffic-related, accident-related, vehicle-related, driver-related, traffic police-related, educational, training, school related, massmedia, community related, health-related and research-related. These should complement each other and work together in a supportive way to tackle the particular children road safety problem in an integrated and sustainable manner that is meant to prevent/reduce children road accidents and improve their road safety.

In pursuing such integrated safety package this research also enhanced the classical 3Es concept (Engineering-Education-Environment) and introduced instead the 14Es honeycomb structure including (Engineering-EducationEnvironment-Enforcement-Egalitarianism-Exposure-Ethics-EmergencyErgonomics-Encouragement-Empowerment-Enabling-Economics-Evaluation).

\section{Pyramid Structure 1: Children Road Safety}

Countries ought to pursue all possible means to prevent children road accidents and relieve their severity, hence achieving acceptable children road safety levels. Such prevention has to be based on a proper diagnostic assessment of the road safety situation. Towards this end this paper starts by developing a conceptualization of the children related road safety pyramid structure, its components and affecting factors see Figure 1.

Towards the base of the pyramid is traffic exposure representing the extent (intensity) and form (nature) of how children as road users are exposed to traffic. As the pyramid base is the biggest it is chosen to represent traffic exposure being the highest activity. On the other hand, the form of traffic exposure can be defined as the way children as road users are exposed to the traffic environment. The second level of the children road safety pyramid represents what could be referred to as the prevailing children road safety culture. In this research, children road safety culture is defined as the cultural environment in which children road safety issues are dealt with as well as the level of awareness of the various 


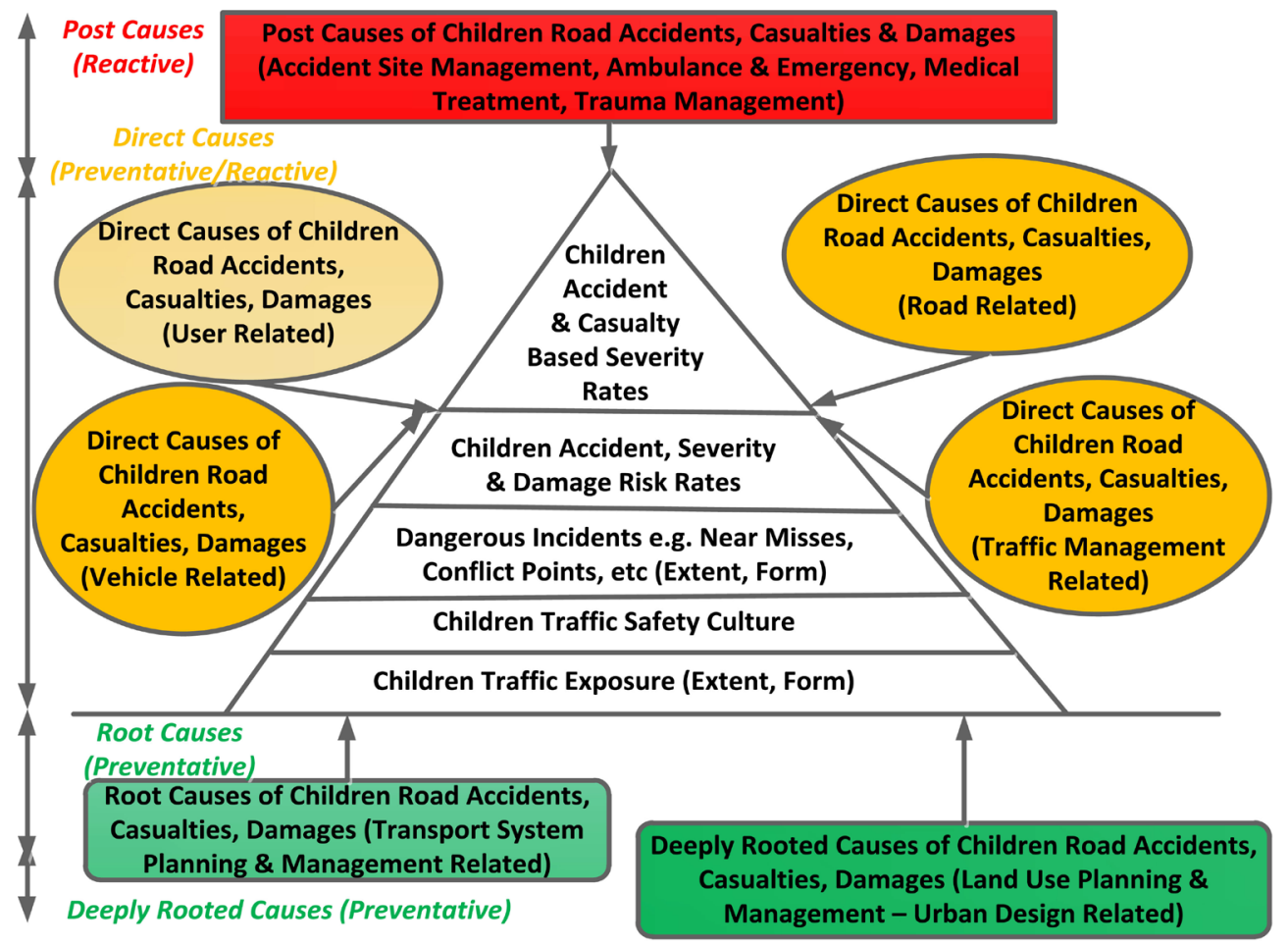

Figure 1. Pyramid Structure 1-Components \& Causes of Children Road Safety, Adapted from [2].

stakeholders involved with children road safety issues. The third level of the road safety pyramid represents the extent and nature of occurring dangerous incidents. This can be expressed in terms of number and severity of incidents such as near misses, conflict points, evasive maneuvering, etc. The fourth level of the children road safety pyramid represents traffic risk rates. These are indicators relating frequency of children accidents, casualties, fatalities, injuries as well as damages to various exposure measures. Such indicators when computed are representative of probability of children accident occurrence. Finally, towards the top of the children road safety pyramid are what can be referred to as severity rates. These indicators are meant to express probability of a children accident resulting into fatalities or a degree of injury or the probability of a children casualty being a fatality or an injury. These are computed by relating the number of children fatalities or injuries either to the number of children accidents or to the number of children accident casualties.

In developing the children road safety pyramid, factors contributing to occurrence of children accidents were identified. These are grouped into four main categories. Such categorization is based on the nature and time frame of the effect of these factors (causes) on the five components describing children road safety. Identified causes include:

- Deeply rooted causes of children accidents, casualties and damages. These are causes related to the pre-effect of unsafe land use planning and management on children traffic exposure extent and form.

- Root causes of children accidents, casualties and damages. These are related to the pre-effect of unsafe transportation planning and management on 
children traffic exposure extent and form.

- Direct causes of children accidents, casualties and damages. These can be further categorized into four groupings, namely road related, user related, traffic management related and vehicle related. These four factors are known to be directly contributing to the occurrence of both dangerous incidents as well as actual children road accidents with varying severity.

- Post causes of children accidents, casualties and damages. These are related to factors occurring after a child accident takes place. Such factors include the effect of accident site management, ambulance and emergency management, medical treatment and trauma management. Such factors may reduce or increase the possibility of a child being slightly injured victim to becoming severely injured or a severely injured victim and may be even becoming a fatality.

\section{Pyramid Structure 2: Children Road Safety Assessment}

The second pyramid structure, referred to as the road safety assessment pyramid, and depicted in Figure 2 shows the 3 main cornerstones required to represent a detailed methodological children road safety diagnostics. This includes as the first cornerstone assessing children road safety culture via a set of generic criteria, see [2]. The second cornerstone involves a review, detailed categorisation and computation of the main children road safety indicators. Finally, the third cornerstone is concerned with compiling and analysing children accident records and identifying main and root causes of children road accidents. In the following sections each of the 3 proposed cornerstones for conducting a comprehensive assessment (diagnosis) of children road safety is discussed.

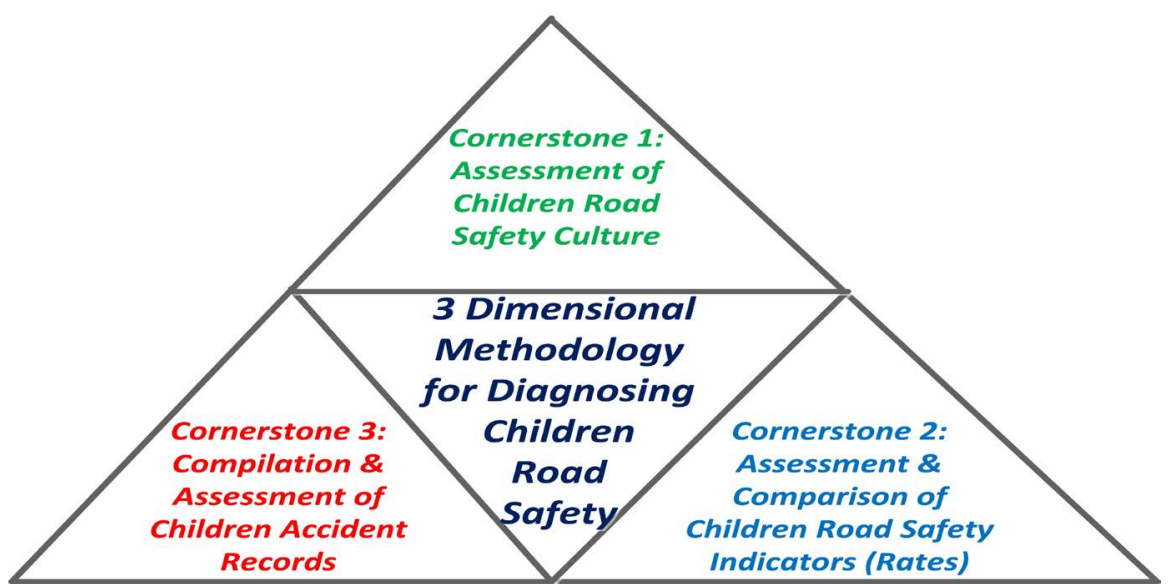

Figure 2. Pyramid Structure 2-Children Road Safety Comprehensive Diagnosis.

\section{Assessment of Children Road Safety Culture}

In this research, the notion of children road safety culture is introduced. Assessing the children road safety culture represents the first step in judging the children road safety situation. The children road safety culture can be represented through 14 aspects as depicted in Figure 3. 


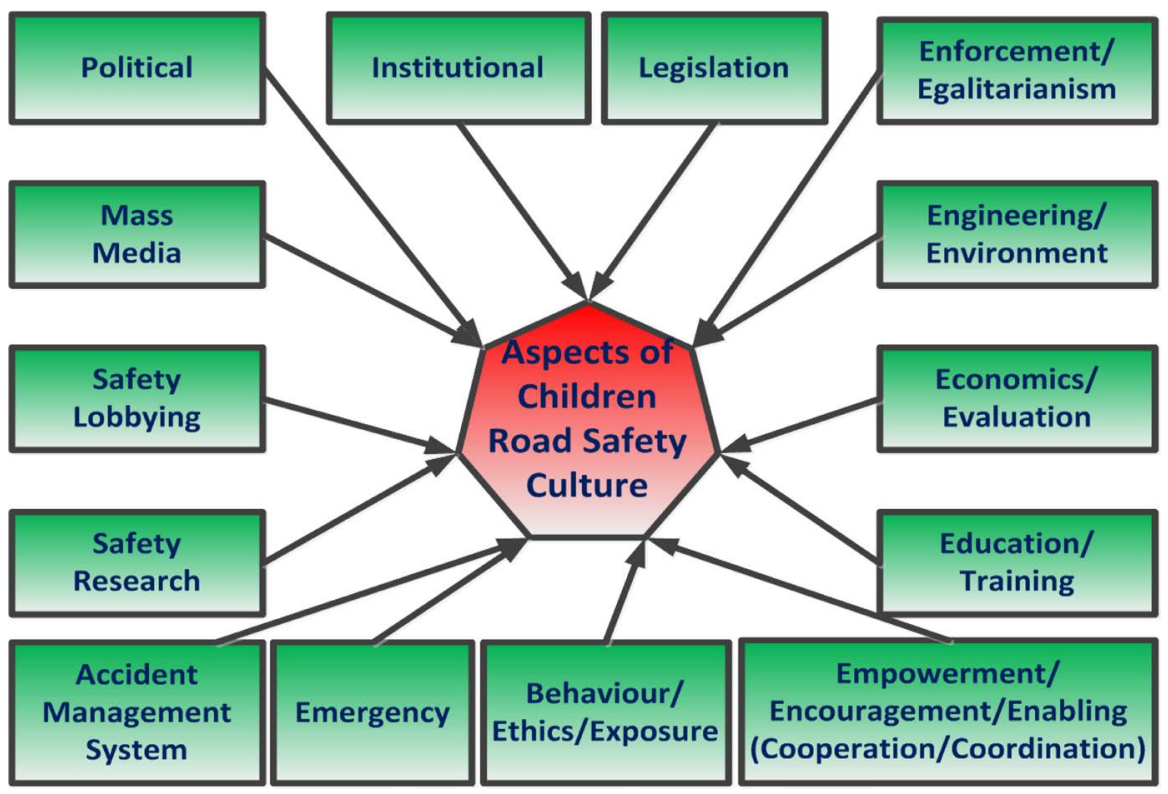

Figure 3. Aspects of children road safety culture.

These aspects are further disaggregated into a number of suggested criterions (more than 40), see Table 1. Based on reviews, interviews, discussions and experience these criteria are semantically diagnosed and described.

\section{Pyramid Structure 3: Children Road Safety Indicators}

Computing children road safety indicators represents the second cornerstone in the assessment of the children road safety situation in a country. Children road safety indicators serve several purposes, namely:

- Identification of safety problems and their intensities

- Determination of road safety levels

- Comparison of road safety levels

- Design of effective accidents' countermeasures

- Evaluation of accident countermeasures

Absolute numbers of traffic accidents, casualties, fatalities and damages do not represent indicative figures to be used for assessment and comparison of road safety. The most meaningful indicators are relative values, see Figure 4 . The figure shows that it is always better, more accurate and indicative to compare children road safety records relative to population, registered vehicles and vehicle kilometers. The difficulty of computing such indicators lies in the difficulty of obtaining the required and accurate raw data needed for their computation. Figure 4 shows the relationship between the difficulties of computation of children road safety indicators versus accuracy of representation of children road safety.

The third pyramid, referred to as the children road safety indicators, shows the levels and types of children road safety indicators, see Figure 5 . These when computed can be used for in depth analysis and historical comparison. Additionally such indicators can be used for cross-sectional snap shot comparison 
Table 1. Children road safety culture-aspects and assessment criteria.

\begin{tabular}{|c|c|}
\hline Aspects of Children Road Safety Culture & Assessment Criteria \\
\hline \multirow[t]{2}{*}{ Political } & Awareness of decision-makers and politicians of Children Road Safety \\
\hline & Goals, policies, targets, objectives on children road safety \\
\hline Institutional & National road safety body \\
\hline \multirow[t]{3}{*}{ Safety Lobbying } & Road safety lobbying including children road safety lobbying \\
\hline & Involvement of international road safety research organizations \\
\hline & Non government organizations concerned with children road safety \\
\hline \multirow[t]{3}{*}{ Safety Research } & National road safety research project including children safety \\
\hline & $\begin{array}{l}\text { Other road safety research include studies on road \& vehicle conditions, children and road-user } \\
\text { behavior, traffic characteristics, legislation/enforcement }\end{array}$ \\
\hline & Children Road safety experts/academics \\
\hline \multirow[t]{2}{*}{ Engineering } & Developed highway standards covering in front of school features \\
\hline & Children Accident reporting system \\
\hline \multirow[t]{13}{*}{ Accident Management System } & Quality \& quantity of completed reporting forms \\
\hline & Maintenance of children accidents data-base \\
\hline & Dissemination of children accident data \\
\hline & Children Accident analysis system \\
\hline & Identification of children accidents locations \\
\hline & Identification of children victims patterns \\
\hline & Diagnosis of direct children accidents causes \\
\hline & Diagnosis of root children accidents causes \\
\hline & Identification of potential countermeasures \\
\hline & Costing of children road safety countermeasures \\
\hline & Valuation of children road accidents \\
\hline & Pre-evaluation of children road safety countermeasures \\
\hline & Post-evaluation of children road safety countermeasures \\
\hline Evaluation & Inclusion of children accident reductions as benefits in highway appraisals \\
\hline Behavior & Road users' respect of traffic rules (children and others) \\
\hline Legislation & Traffic legislation \\
\hline \multirow[t]{6}{*}{ Enforcement \& Standards } & Vehicle inspection \\
\hline & Driving test pass rate \\
\hline & Driving test theoretical part (Signs including school signs) \\
\hline & Driving test theoretical part (Highway Code including driving in front of schools) \\
\hline & Practical part of driving test include driving in front of schools \\
\hline & Special training for traffic police \\
\hline Emergency & High speed emergency service \\
\hline \multirow[t]{2}{*}{ Education } & Separate road safety syllabus for school education \\
\hline & Children traffic parks \\
\hline \multirow[t]{2}{*}{ Mass-media } & Radio and television programs on children road safety \\
\hline & Children Road safety posters and leaflets \\
\hline \multirow[t]{2}{*}{ Coordination \& Cooperation } & Liaison between traffic police and road engineers \\
\hline & Children Road safety week \\
\hline
\end{tabular}




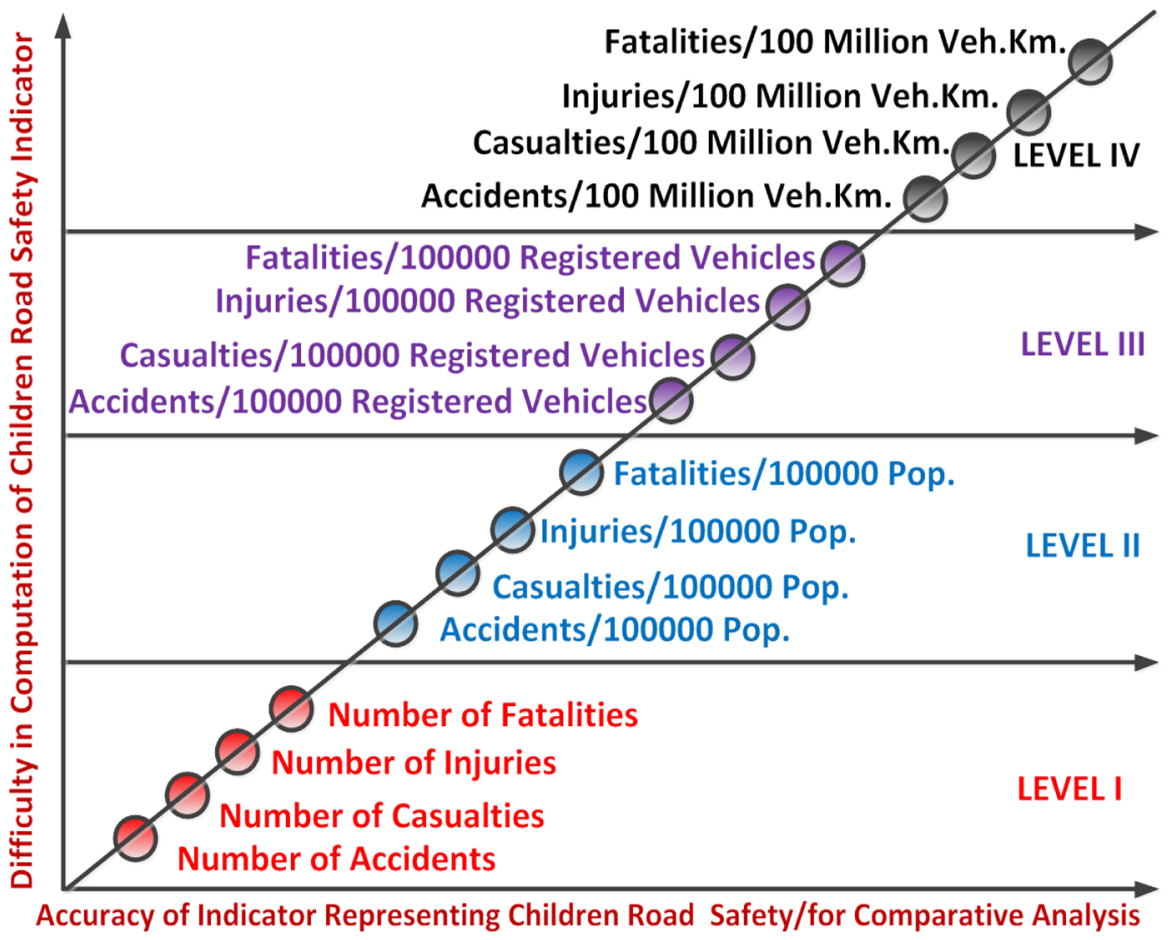

Figure 4. Difficulty of computation of children road safety indicators versus accuracy of representation of children road safety.

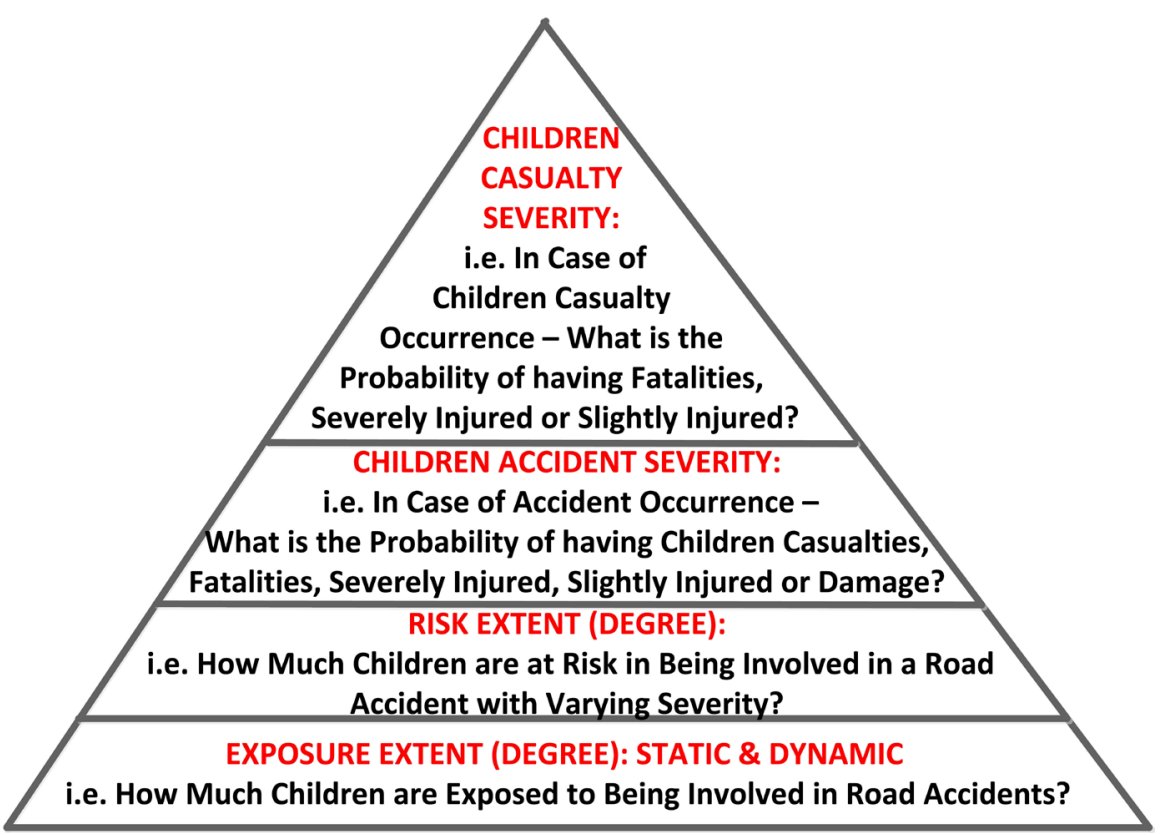

Figure 5. Pyramid structure 3-levels \& types of children road safety indicators.

among countries, cities and provinces. The Figure shows a 4 level hieratical structure of indicators answering 4 generic questions as follows:

1) Exposure Extent (Degree): i.e. how much children are exposed to being involved in road accidents?

2) Risk Extent (Degree): i.e. how much children are at risk in being involved in a road accident with varying severity? 
3) Children Accident Severity: i.e. in case of accident occurrence-what is the probability of having children casualties, fatalities, severely injured, slightly injured or damage?

4) Children Casualty Severity: i.e. in case of children casualty occurrence-what is the probability of having fatalities, severely injured or slightly injured?

\section{Analysis of Children Accident Causes}

Analysis of children road accident records represents the third cornerstone in the assessment of the children road safety situation. Such analysis can identify direct children road accident causes. This should be based on accident database generated out of accident reporting system. Traditionally such reporting forms are completed by traffic police at an accident site. Usually traffic police can mark one or more cause for an accident. These are usually listed and categorized into six categories, namely: driver related causes, pedestrian related causes, vehicle related causes, road related causes, environment related causes and other causes.

The institute for health metrics and evaluation, see [3] identified that children under the age of 19 when involved in traffic accidents are mainly involved as pedestrian (38\%) followed by being involved as vehicle occupants (36\%) followed by being involved as motorcyclists (14\%), other $7 \%$ and as cyclists (6\%), see Figure 6.

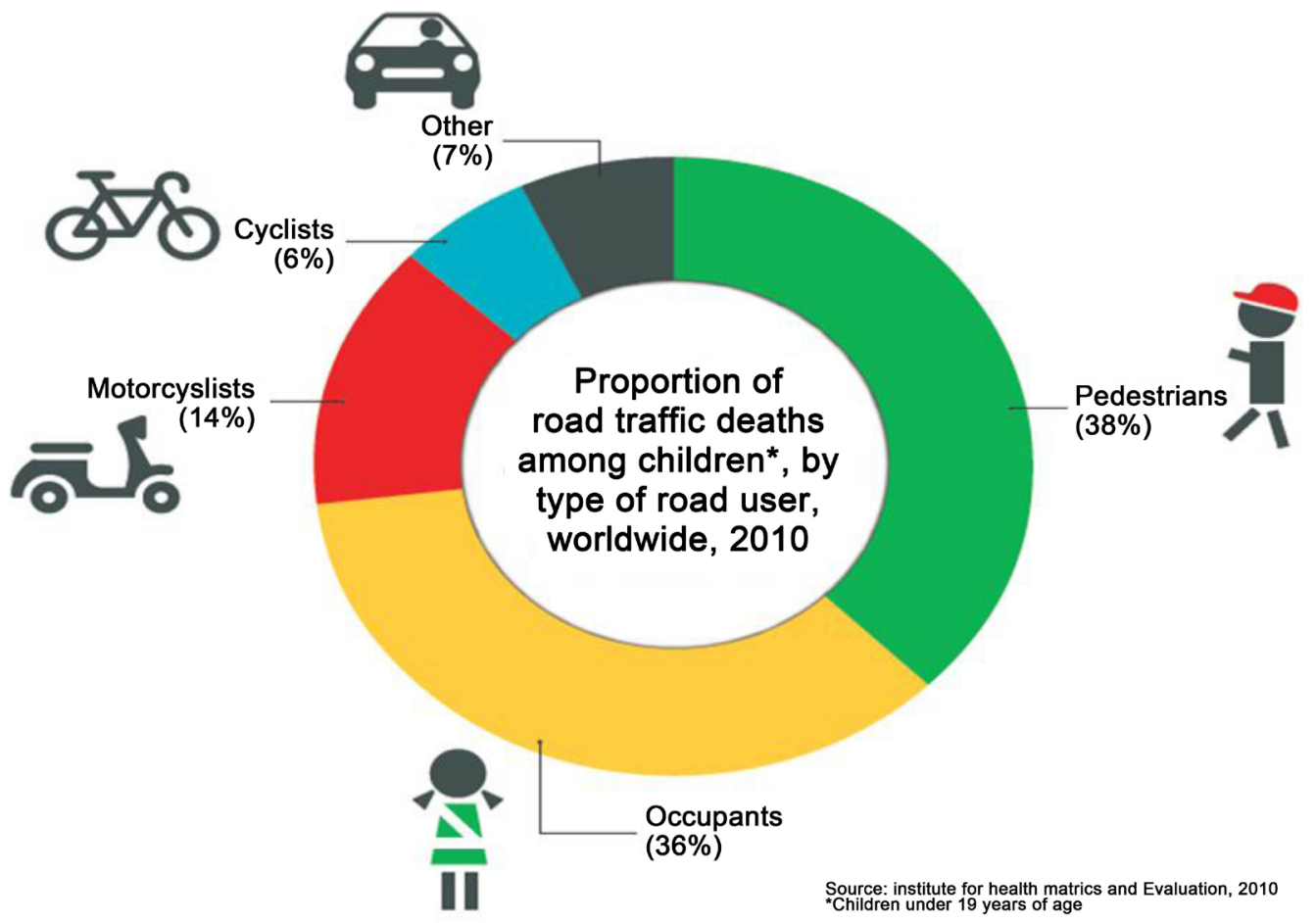

Figure 6. Types and pattern of children road accidents worldwide.

\section{Conceptual Model of Children Road Safety Behaviour}

It is known that accidents/incidents are a function of exposure and risk of getting involved in an accident/incident. In order to maximise children road safety, 
three factors has to be taken into account as shown in the following model.

Children Road Safety = Maximise (Children Road Safety Behaviour) + Maximise (Other User Road Safety Behaviour) + Minimise (Road \& Vehicle Risk)

At the core of the paper is the development of a conceptual model of factors affecting the road safety behavior of children taking into consideration what has been previously reported in [4]. Towards this end, the paper presents the fourth pyramid, referred to as the children road safety behavior pyramid. This includes a 7 level hierarchal structure starting from exposure leading to experience to skills/abilities, to knowledge to perception to attitudes and eventually culminating in children road safety behavior, see Figure 7 .

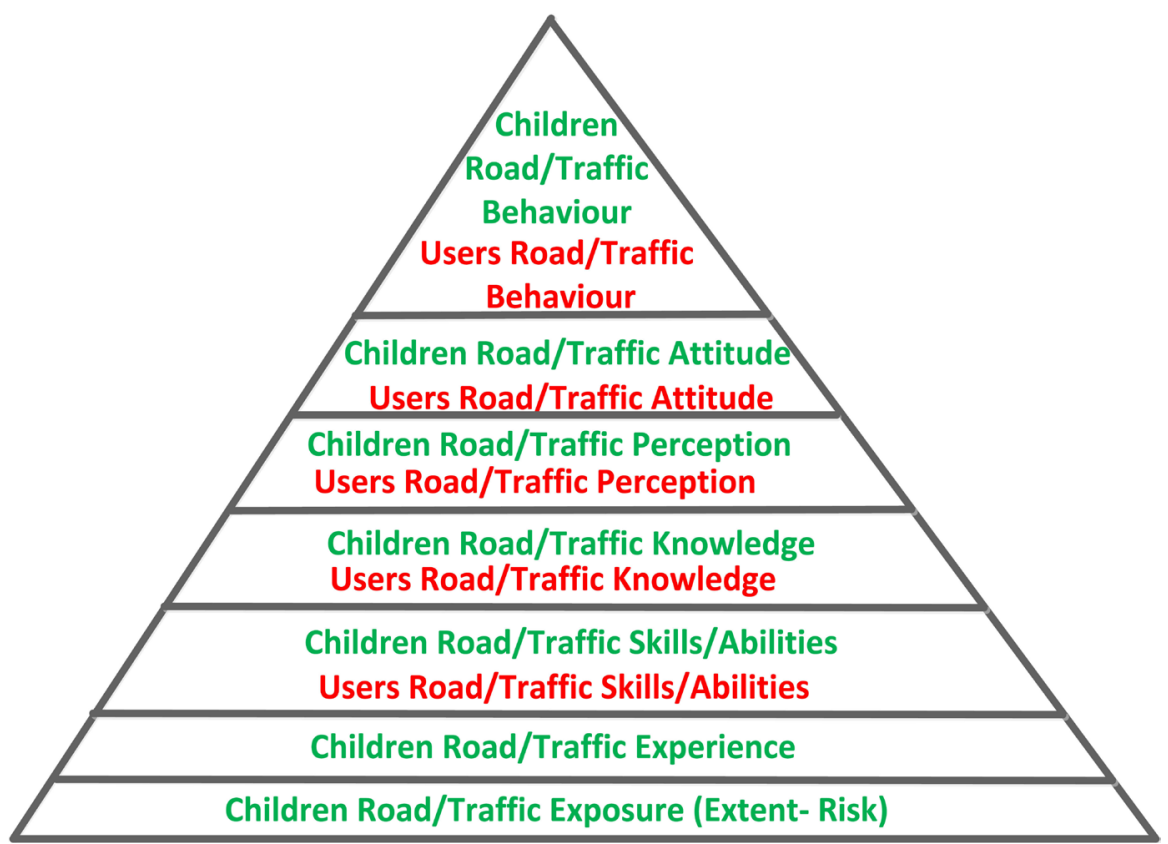

Figure 7. Seven levels hierarchal structure starting from exposure culminating in children road safety behavior.

The following model also illustrates the factors affecting children road safety behavior in a functional form.

Children Road Safety Behaviour

$=$ function (exposure, experience, skills, knowledge, perception, attitudes)

These factors should be targeted to enhance the existing levels of children road safety behavior. Improvement of these factors act as core basis for developing children road safety packages covering aspects such as education and training, engineering, legislation and enforcement, and publicity. These factors are detailed in Figure 8 and explained as follows:

Children traffic exposure can be explained in two contrasting ways. The first is that the more a child is exposed to deal with traffic, the more traffic experience he/she gains. This will lead to improving children's cognitive traffic skills and 


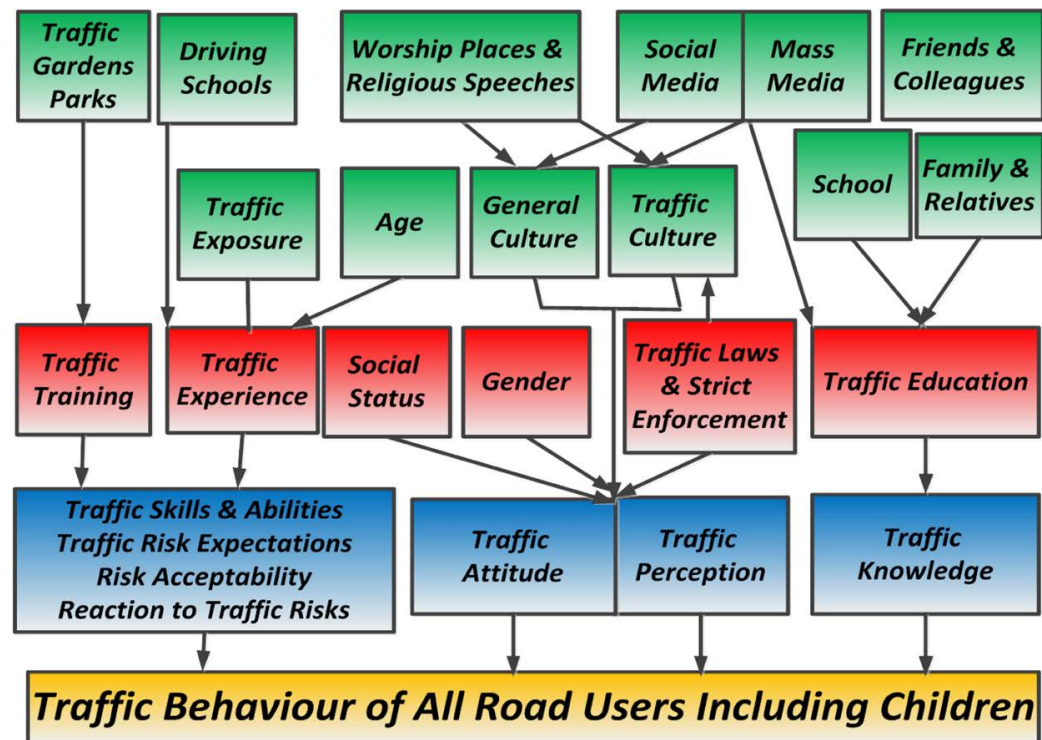

Figure 8. Conceptual model of children road safety behaviour.

abilities (i.e. anticipation of traffic risks) as well as improving their perceptual skills (i.e. reacting to anticipated risk and risk acceptance). On the other hand, one can say that the more a child is exposed to traffic situations, the more likely that he/she is at risk of becoming involved in a traffic accident. Many children may have their schools within walking distances others may have it far from their homes and may walk, use school bus or other mode of transport or being driven or escorted by parents or other family members. Walking to and leaving school on their own involves a considerable part of children being exposed to traffic and accident risk. In many countries when children arrive early at school they may unfortunately be allowed to stand in front of school and not to stay inside. This may lead to unsafe children behavior and exposure to traffic.

Children traffic experience is mainly a function of the level of traffic training, the age and the extent of traffic exposure of children. The older a child is the more likely that he/she has longer experience with traffic.

Children traffic knowledge which in turn is a function of children traffic education and information. Different parties are involved towards the teaching of children on how to deal with traffic. These include: parents, schools, clubs, media, other. However, it is mainly the schools and the parents who together share the responsibility for educating and training their children on how to deal safely with traffic. Safety education at schools is a function of how developed and advanced is the road safety curriculum in terms of content, quality of presentation material, number of hours, and whether it is mandatory or voluntary. Previous research showed that the type of schooling and the affluence of the district where a school is located could be major factors influencing children's' traffic knowledge and hence traffic behaviour.

Children cognitive skills and abilities (i.e. anticipating traffic risks) as well as perceptual skills (i.e. reaction to anticipated risk and risk acceptance) which in turn is a function of children traffic experience. Children should be aware that in 
order to cross a street they have to look to cross - make sure traffic is far enough - continue to look while crossing and definitely do not run and panic. Sometimes, in extremely hazardous situations, running might be the only safe crossing option available for a child. However, these hazardous situations are probably the outcome of poor selection of crossing points and/or poor estimation of crossing gap. Crossing in a group can represent a situation where each child is implicitly relying on the others judgment of traffic as well as having a feeling of being protected by the group regardless of the selection of the correct point for crossing or the crossing gap.

Children traffic perception/attitude which in turn is impacted by children home, school and road environments including the extent of traffic police presence, behavior and level of enforcement. This includes points such as feeling of independence amongst the children and willingness to travel to and from school and other destinations on their own. On the other hand it also includes feelings of fear of traffic, fear of being involved in a traffic accident, fear of cars traveling at high speeds. Issues such as children looking for specific places to cross from and whether they would hold hands when crossing roads with other adults are also a part of the formation of children traffic perception/attitude.

Several techniques can be employed to measure the traffic behaviour of children as well as to measure the factors affecting this behaviour. Some of these measures include: attitudinal surveys involving open-ended interviews and/or structured questionnaires, pictorial and slide questions as well as video based questions, laboratory tests with a model, observation of simulated conditions on a test track, and observations of real road situations.

\section{Developing a Generic Integrated Children Road Safety Package}

Realising that today's children constitute a major part of today's pedestrians as well as tomorrow's drivers and pedestrians, this research develops a generic and comprehensive road map to improve the children road safety situation. Based on the previous analysis, reviews, conclusions, author's experience and discussions with several experts and officials, the paper develops an integrated children road safety package. This is composed of various policies, measures, actions and initiatives targeted to improve children road safety. These are categorized into 18 topical fields of action namely: institutional, land use planning and management, travel demand management, road infrastructure improvement, legislation, traffic-related, accident-related, vehicle-related, driver-related, traffic police-related, enforcement, educational, training, school related, mass-media, community related, health-related and research-related measures, see Figure 9.

These should complement each other and work together in a supportive way to tackle the particular children road safety problem in an integrated and sustainable manner that is meant to prevent/reduce children road accidents and improve their road safety. These when pursued in an integrated manner are expected to enhance the traffic safety conditions for children as well as to improve their accessibility and mobility environment. This can also act as a prototype 


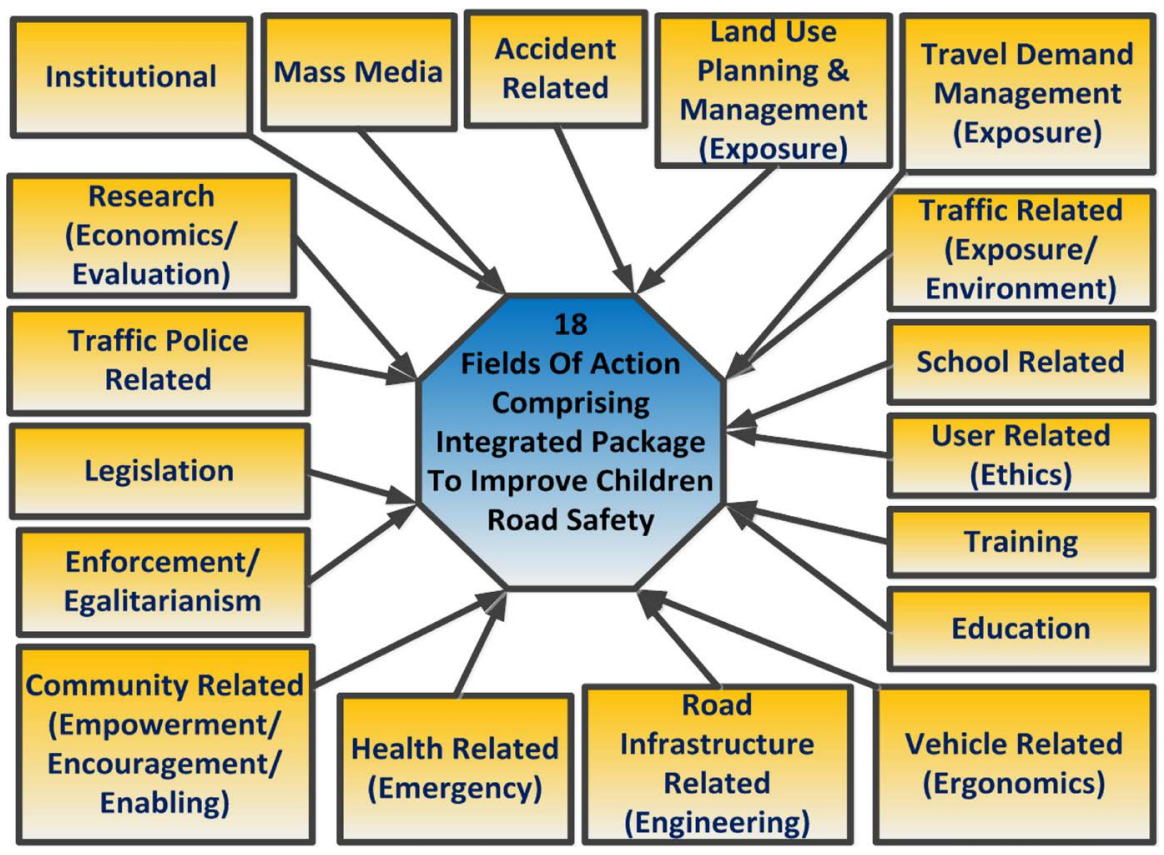

Figure 9. Integrated children road safety package comprising 18 fields of action.

guideline/check list for countries across the world in compiling and tailoring their children road safety programmes.

\section{Developing a Generic Honeycomb Structure of Road Safety Elements}

In pursuing such integrated package this research also re-engineered the classical road safety elements comprising the 3Es cornerstones, namely Engineering, Education \& Enforcement and instead developed and introduced the 14Es honeycomb structure of road safety elements. The honeycomb structure is meant to demonstrate the inter-dependability and importance of integration of all $14 \mathrm{E}$ elements to tackle road safety in a comprehensive and holistic manner. The 14Es elements shown in Figure 10 include:
1) Engineering
2) Education
3) Enforcement
4) Environment
5) Evaluation
6) Egalitarianism
7) Exposure
8) Ethics
9) Emergency
10)Ergonomics
11)Encouragement
12)Empowerment
13)Enabling
14)Economics 


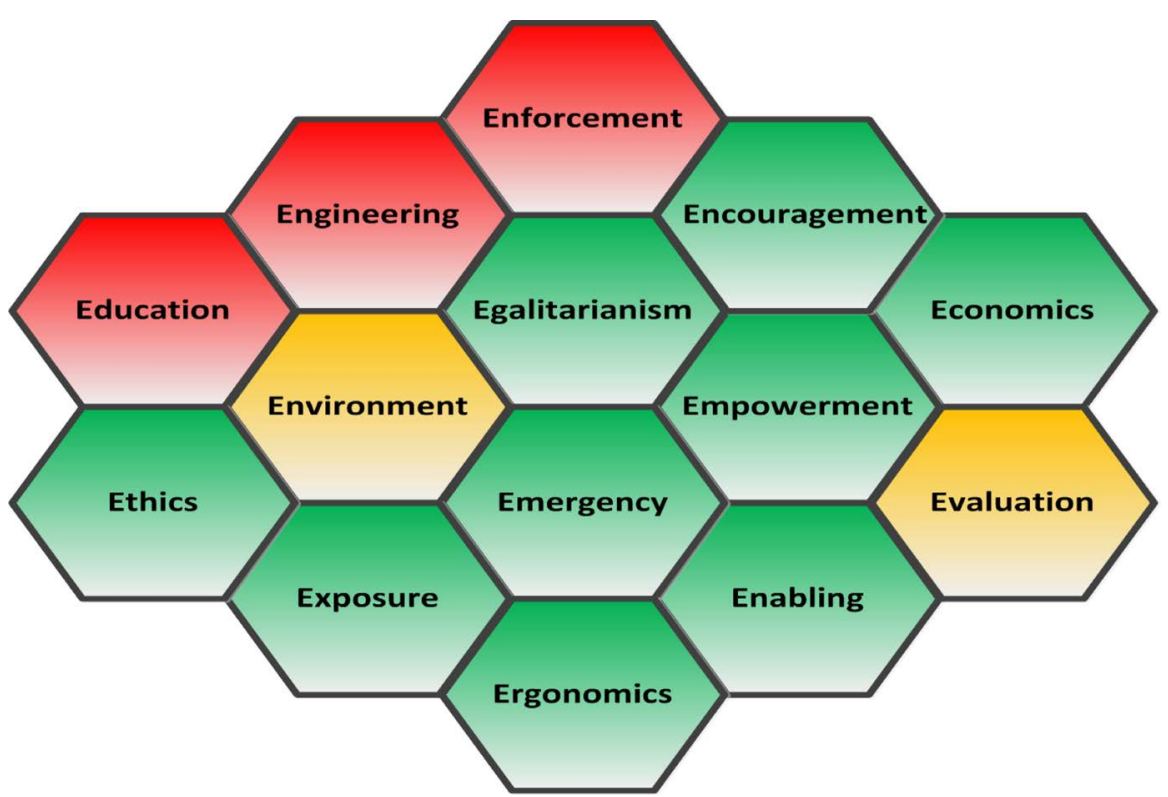

Figure 10. Integrated children road safety strategy comprising 14 Es Elements (From 3Es in Red to 5 Es in Orange to 14 ES in green introduced in this research).

\section{A Prototype Integrated Children Road Safety Package}

\section{Institutional}

- Establish a proper institutional framework to support and ensure continuity of implementation of road safety activities including children safety. This should have the necessary authority to enable it to work and coordinate all road safety efforts conducted by different authorities and organizations. This could take the form of a National Road Safety Council to cut across several government/nongovernmental bodies advising government on policy formulation for road safety activities. Such council should have support at highest government level and should also have a legal entity.

- Establish a road safety unit to implement programmes pertaining to road safety. Such unit should draw expertise from various institutions such as transport academics, traffic police, road safety experts, psychologists, doctors, educationist, social workers, etc. The unit should have provincial/district offices to provide in field backup.

- Integrating and coordinating the roles that should be played by the different parties responsible for educating and training children on traffic safety. These parties include: ministry of education (schools), ministry of transport, parents, ministry of interior (traffic police officers), traffic safety experts, ministry of information (mass media including television, radio, newspapers).

\section{Legislation}

- Issuing laws that grant traffic police more enforcement authority to inflict penalties to traffic violations in front of schools.

- Stringent penalties for in front of school violations should be adopted. Penalty package to include warnings, penalty points, on the spot fines, traffic 
driving license withdrawal, driving suspension, suspended imprisonment, driving license revoking.

- Legislation penalising parents for violating traffic rules/ regulations, such as crossing carriageway with their children at dangerous or non-designated crossing locations.

- Legislation to be developed that strictly and totally prohibits drinking and driving especially when children are on board.

- Legislation penalizing drivers allowing children on board without seat belts/ safety helmets.

- Low speed limit zones should be established in front of schools.

- Drivers applying for driving licenses should demonstrate their knowledge of children road safety rules and regulation.

- A legislation for road safety education to be compulsory at schools.

- Legislation for licensing driving schools should be drawn according to preset stringent standards including training drivers on how to drive in front of schools.

- A legislation on low speed limits in front of schools.

\section{Enforcement (Egalitarianism)}

- Develop traffic court systems capable of promptly handling traffic violations and inflicting appropriate rulings especially for children safety related violations

- Develop computerized databases to allow traffic courts to identify repeated children safety violations and inflict proper and consistent rulings.

- Strong and adequate enforcement of traffic laws in front of school entrances.

- Prohibition of parking in front of schools' entrances and crossing points. This is meant to prevent occurrence of hazardous situations both for school children attempting to cross roads behind parked vehicles, as well as for car drivers not seeing children while attempting to cross from behind parked cars. In addition, heavy vehicles access should be strictly controlled.

- Crossing police patrols to be located at busy crossing points to assist children to cross these roads while walking to and leaving their schools.

- A traffic police officer to be present in front of each school at the times of start and finish of school days so as to ensure safe crossing of children. This is particularly important for those schools whose entrances are on heavily trafficked roads.

- A common phenomenon in front of schools in many developing countries is to see petty sellers standing in front of schools and small stalls occupying schools' sidewalks and obstructing the footways. In addition to the obvious health issues this creates, a hazardous traffic situation can also be induced as children tend to gather around these stalls in a disorganized, incautious manner that might expose them to the danger of approaching traffic. Petty sellers and hawkers should be prohibited from standing in front of schools.

- Traffic police to be well trained and equipped. Training should include how to deal with an accident involving children in terms of accident reporting, 
dealing with victims if any, clearing accident sites, etc.

- Enforce penalizing/prohibiting illegal occupation of sidewalks whether by parked vehicles/stall holders/hawkers/petty-sellers/ribbon development on densely trafficked roads.

Land Use Planning \& Management (Exposure)

- Land use and transport planners should be heavily involved in determining the safe location and distribution of schools among residential areas.

- Allocating substantial space for school playgrounds to attract children to stay inside schools and not to hang around outside schools.

- School entrances to be studied and located at lightly trafficked side-roads.

- Ensure compatibility of land use types adjacent to schools i.e. land use types that do not attract very heavy or commercial traffic.

Travel Demand Management (Exposure)

- Provision of school transport buses and public transport facilities that offer premium levels of service to encourage parents and children to switch from using cars travelling to/from and into using public transport.

- Stagger and select off-peak traffic hours for the start and the end of the school day to avoid peak periods characterized by high traffic density.

- Provision of non-motorised (walking and cycling) transport facilities that offer a real alternative to encourage parents and children to switch from using cars travelling to/from and into using non-motorised transport systems.

\section{Traffic-Related (Exposurel Environment)}

- Traffic calming measures including: speed control humps, rumble areas, rumble strips, jiggle bars, and school warning signs should be installed, and continuously maintained, in front of all school entrances. These measures are meant to reduce the number and the severity of children/vehicle conflicts.

\section{User Related (Ethics)}

- Develop specifications/standards for driving schools to include training novice drivers on how to drive, park and maneuver in front of schools. Drivers should be extra cautious and aware when driving near schools.

- Update national driving handbooks to include rules and regulation on how to drive in front of schools.

- School bus attendants to assist children in boarding and alighting of buses towards safe locations as well as escorting very young children to safe off street locations.

- Management of pick up and dropping of children in front of schools.

- School patrol crossings and community assistance should be encouraged.

- School bus drivers should ensure dropping children on the road off side.

- Inclusion of instructions on how to drive in front of schools in driving tests.

- On dropping children from school buses, bus drivers should ensure dropping children on the same side of the road as child's destination. In case this is difficult, the bus teacher should escort the child while crossing the road.

\section{Education}

- A strong commitment towards road safety education where road safety to be 
a separate, graded subject at all schools.

- Developing teachers' guidelines for instructing teachers on how to teach road safety for school children.

- Focus efforts towards designing attractive educational curricula and training materials. This includes: posters, leaflets, booklets, brochures, slides, films, videos, stories, road safety quizzes.

- Road safety curricula should cover topics such as: where to play safely, how to cross roads, understanding traffic signs and signals, getting to school safely, identifying local dangerous spots, seeing and being seen by traffic, judging distances and speeds, etc.

- Involvement of traffic safety experts in developing educational and training materials as well as in giving talks and lectures. Programs of road safety talks to be given by police and traffic safety experts in schools.

- Parents should educate, train and prepare their children from an early age on how to deal with different traffic situations.

\section{Vehicle-Related (Ergonomics)}

- Develop vehicle standards and specifications to include sufficient children safety features within cars (Ergonomics) and outside.

- Ensure that all cars are equipped with seatbelts at front and back seats as well as front seat air bags.

\section{Road Infrastructure Related (Engineering)}

- More use of intersection designs that are speed-self reducing especially in residential areas. These include: roundabouts, curves at $\mathrm{T}$-junctions.

- Provision of adequate street lighting in front of schools.

- Sidewalks to be wide enough to allow for a more comfortable and easy movement for children and parents.

- Kerbs to be dropped at children crossings to ease such crossing.

- Crossing to be staged, on wide roads, through central refuge islands to allow parents and children to negotiate one traffic stream at a time.

- Hazardous locations such as open gutters, open electricity kiosks to be fenced with visual and audible warning signs.

- Road closure or limiting access in front of schools should be considered.

- Construction of pedestrian bridges/tunnels to enable segregated children pedestrian crossing of main roads.

Health-Related (Emergency)

- Quick emergency service using latest equipment for communication, well trained first aid officers, and high-speed mode for victim transportation.

- Training of traffic police officers on first aid \& promoting public first aid awareness.

- Coordination of accident rescue operations among traffic police officers, first aid and emergency officers and hospitals.

\section{Community-Related (Empowerment/ Encouragement/ Enabling}

- Develop specialized training and educative children programs to increase their knowledge of road safety aspects. 
- Promote road safety through the community and help encourage the formation of non-government voluntary organisations who are particularly interested in children road safety.

\section{Accident-Related}

- Attention to be given to the whole process of children accident data collection, storage, and analysis to systemize and ensure that it is functioning in an adequate and efficient manner. A reliable children accident database is crucial for children safety improvement.

\section{Information \& Mass-Media}

- Promoting and raising society awareness of potential traffic hazards for children.

- An annual traffic week or a monthly traffic day should be developed. This involves concentrated mass media campaigns on children road safety aspects, press articles, exhibitions, competitions, posters, leaflets and pamphlets.

- Television and radio interviews with officials responsible for children road safety such as traffic police officers, academics, engineers, doctors, and teachers.

- Promoting and raising society awareness of the potential traffic hazards and problems encountered by school children. This can be achieved through mass media campaigns aimed at promoting drivers' safety consciousness and parental responsibilities.

- Television programs should be screened to avoid the display of programs shots and films inducing in children unsafe and reckless traffic behavior.

- Media campaigns should concentrate on disseminating knowledge to the public regarding safe use of the road, as well as attempting to change unsafe traffic attitudes.

\section{Training Related Measures}

- Cognitive and perceptual skills as well as positive safe attitude ought to be acquired by children and enhanced. Road safety training should be compulsory in schools. Training can be at simulated environments in school yards or at traffic parks, or using audio-visual 3 dimensional films or computer simulation.

- Train children in a real environment. Children should be taken to suitable real road sites especially in the neighborhoods of their homes and schools to learn and experience road safety.

- Construct children traffic parks to educate and train children of safe practices when dealing with the traffic environment.

- Traffic parks/gardens simulating real road conditions should be developed. Children to be trained, through role play exercises, on how to deal with traffic situations.

- Planned and continuous training of trainers on children road safety (teachers/instructors/people involved in community programs) is an absolute necessity to efficiently and effectively perform their mission.

- Organize training courses, seminars, and lectures for engineers, professionals 
and technicians in areas of road safety.

\section{School Related Measures}

- Schools should keep their gates opened from early morning before the starting school hours and until late evening after end time of the school day. This is meant to give those children arriving early and leaving late from school the chance to stay inside school rather than hang around in front of their schools and be exposed to potential traffic hazards. Children should be prohibited from staying outside their schools.

- Management of pick up and dropping of children in front of schools. School patrol crossings and community assistance should be encouraged.

\section{Research-Related}

- Special grants to conduct children road safety research and consistency maintained.

- Organize national and international children road safety conferences.

- Easy and accessible dissemination of children accident data to all interested organizations/individuals that need to use data particularly for research.

- Special research grants to conduct children traffic safety research should be offered and consistency maintained.

- A reliable accident data base is crucial for any safety research. Attention to be given to the whole process of children accident data collection, storage, and analysis to systemise this process and ensure that it functions in an adequate \& efficient manner.

- More children behavioural studies to look at exact kind of relationship between traffic knowledge, cognitive processes and attitudes or motivation of children, the development process with respect to formation of traffic attitudes and the way differences between gender, age, socio-economic levels, culture, level of education of children affects traffic behaviour.

- School children should be monitored in real world situations. This can be achieved by personal documented observations, and/or monitoring using video cameras. These observations together with the interpretation of the video films recordings can be analysed for the purpose of inferring the pattern of actual traffic behaviour of school children as well as the difficulties that limit their mobility and the traffic hazards that they encounter.

- Future research should attempt to identify and define the adequate desired traffic behaviour for school children. The expected gap between actual levels of traffic behavior, factors affecting it and the desired levels can then be identified both in a quantitative and qualitative terms.

- Future studies should also look at the level of service of movement on sidewalks and while crossing roads (volume, density, speed, delays).

- Further studies should be looking at drivers behaviour in front of schools and their knowledge and awareness of traffic rules in front of schools.

- It is crucial to value traffic accidents so as to economically evaluate the worthiness of remedial measures. In valuing children traffic accidents, several quantitative as well as qualitative factors ought to be considered. Basically the 
notion of "Children being the Future of Tomorrow" has to be emphasised.

\section{Conclusions}

In this research, a generic pyramid structure approach was proposed to assess and improve children road safety. The structure is composed of 4 hierarchical pyramids. The first referred to as the road safety pyramid, is meant to represent the road safety components and levels in a comprehensive and structured manner. It describes the factors constituting children road safety including root, at accident and post accident factors. The second pyramid, referred to as the children road safety assessment pyramid, showed the 3 main cornerstones required to represent a detailed methodological children road safety diagnostics. The first corner involves assessing the road safety culture via 14 aspects; the second corner covers the computation and analysis of children road safety generic indicators while the third corner includes compiling and analyzing children accident records.

The third pyramid representing the children road safety indicators, shows the levels and types of children road safety indicators that when computed can be used for in depth analysis and historical comparison. Additionally such indicators can be used for cross-sectional snap shot comparison among countries, cities and provinces.

At the core of the paper was the development of a conceptual model of factors affecting the road behavior of children. Towards this end, the paper presented the fourth pyramid, referred to as the pyramid representing children road safety behavior. This includes a 7-level hierarchal structure starting from exposure leading to experience leading to skills/abilities, to knowledge to perception to attitudes and eventually culminating in children road safety behavior. These factors should be targeted to enhance the existing levels of children road safety behavior. Improvement of these factors act as core basis for developing children road safety packages covering aspects such as education and training, engineering, legislation and enforcement, etc....

The paper concludes by developing a generic integrated children road safety package of policies, measures, actions \& initiatives. This is meant to act as a guideline/check list for countries across the world in compiling and tailoring children road safety programmes. Programmes are meant to enhance the traffic behavior of children as well as to improve their road environment. The package is composed of 18 fields. These should complement each other and work together in a supportive way to tackle the particular children road safety problem in an integrated and sustainable manner that is meant to prevent/reduce children road accidents and improve their road safety. In pursuing such integrated package this research also enhanced the classical 3Es concept and introduced instead the 14Es concept. In conclusion to improve the children road safety situation in a country, city or province suggested safety package ought to be coordinated and applied within an integrated traffic safety management program. 


\section{References}

[1] World Health Organization (WHO) (2015) Global Status Report on Road Safety.

[2] Abbas, K.A. (2004) Assessment and Improvement of Road Safety in Developing Countries: Egypt as a Prototype Case Study. Advances in Transportation Studies, 1, 5-24.

[3] Institute for Health Metrics and Evaluation (IHME) (2010) Data Visulaizations.

[4] Abbas, K.A., Mabrouk, I. and Al-Araby, A.K. (1996) School Children as Pedestrians in Cairo: Proxies for Improving Road Safety. Journal of Transportation Engineering, 122, 291-299. https://doi.org/10.1061/(asce)0733-947x(1996)122:4(291)

Submit or recommend next manuscript to SCIRP and we will provide best service for you:

Accepting pre-submission inquiries through Email, Facebook, LinkedIn, Twitter, etc. A wide selection of journals (inclusive of 9 subjects, more than 200 journals)

Providing 24-hour high-quality service

User-friendly online submission system

Fair and swift peer-review system

Efficient typesetting and proofreading procedure

Display of the result of downloads and visits, as well as the number of cited articles Maximum dissemination of your research work

Submit your manuscript at: http://papersubmission.scirp.org/

Orcontact jtts@scirp.org 